International Journal of Instruction e-ISSN: 1308-1470 • www.e-iji.net
October $2020 \bullet$ Vol.13, No.4

p-ISSN: 1694-609X

pp. $975-986$

Received: 21/10/2019

Revision: 28/05/2020

Accepted: 19/06/2020

OnlineFirst:11/09/2020

\title{
Positive Anxiety and its Role in Motivation and Achievements among University Students
}

\section{Salwa Al Majali}

Al Ain University, Abu Dhabi, United Arab Emirates, salwa.almajali@aau.ac.ae

Recently, psychologists and educators have been interested in the study of anxiety, motivation and achievements. The modern approach to the phenomenon of anxiety is based on the fact that anxiety should not be regarded as an initially negative personality trait; it is a signal of inadequacy of subject's activity in relation to the situation. Each person is characterized by the optimal level of anxiety, the socalled positive anxiety, which is a necessary condition for the development of personality, and there is a set of anxiety situations - depending on the experience and personal resources. The relevance of the research topic is explained by the constant updating of the content of education. The latter often leads to meager understanding by students of their future profession and influences the formation of students' self-regulation techniques, necessary for a favorable independent learning and active life position. The purpose of this study is to determine the effect of anxiety on motivation and performance. The results of the study showed that $49 \%$ of high-performing students have a medium level of anxiety, and $41 \%$ are highly anxious. High rates of internal and external motivation are among respondents with an average value of situational anxiety. Significantly lower motivation is in students with a high level of trait anxiety. A high level of anxiety contributes to a high level of academic achievement, but at the same time reduces the motivation for learning. A low level of anxiety leads to a decrease in academic performance, but the level of motivation is quite high. Therefore, the results of the study can be useful for teachers, university management, as well as for those who are responsible for the preparation and conduct of examination sessions.

Keywords: motivation, anxiety, achievement, amotivation, the academic motivation scale (AMS), the state-trait anxiety inventory, anxiety

\section{INTRODUCTION}

Academic achievement and motivation play an important role for students (Muro et al., 2018). Academic achievements are important because they greatly influence a person's future success (Steinmayr et al., 2014, Kumaraswamy, 2019). The success of students in higher education is influenced by many factors: financial situation; health status; age;

Citation: Majali, S. A. (2020). Positive Anxiety and its Role in Motivation and Achievements among University Students. International Journal of Instruction, 13(4), 975-986. https://doi.org/10.29333/iji.2020.13459a 
marital status, as well as individual psychological characteristics of students (Hailikari et al., 2018, Hol et al., 2017, Toraman et al., 2020). The achievement motivation is aimed at a certain end result, obtained due to the characteristics of a person. Namely, to achieve success or avoid failure. Achievement motivation is characterized by a constant review of goals (Khalaila, 2015). Students are in a period of intense socialization of a person, the development of higher mental functions, the formation of the entire intellectual system and the personality as a whole, high cognitive motivation ( $\mathrm{Su}, 2016)$. Motivation plays an important role in the educational process. If the abilities are not high enough, then positive motivation can act as a compensating factor. However, if there is no motive for education, then even a high level of ability cannot compensate this (Kenny et al., 2010; Guo et al., 2015). The motivation of educational activity is the correlation of the student's goals, which he/she seeks to achieve, and the internal activity of the individual. In learning, motivation is expressed in the student's acceptance of the learning goals and objectives as personally significant and necessary (Wigfield, et al. 2006; Rana \& Mahmood, 2010). Student's achievements are an important learning outcome. As a result of their experience in an academic course, students must master a certain content, which is confirmed by their results in exams. Scientists associate student performance with many variables, including student test anxiety and teacher assessment methods (Hancock, 2001).

Many scientists explore the relationship between anxiety and achievement motivation (Dweck \& Wortman, 1982; Hancock, 2001). The effect of anxiety on student performance was studied in this meta-analytical study. In total, 328 scientific studies were collected during the literature review, of which 151 were included in the metaanalysis. 151 scientific studies were compiled to obtain a sample of 115,086 subjects. The results of the random effect model showed that anxiety has a negligible positive effect on student performance (Erzen, 2017).

Students who experience a high level of anxiety most often do poorly in learning (Jing, 2007; Mondal et al., 2013). Anxiety can have a negative effect on academic performance, which is emphasized in Eysenck's theory of close monitoring. Anxiety impairs the effective functioning of students' attention systems and increases the degree to which processing efficiency depends on attention control. Thus, this explains the effect of anxiety on students' attention processes and cognitive functions. In this regard, anxiety can reduce academic performance (Eccles \& Wigfield, 2002; Eysenck et al., 2007). Feelings (affective) and anxieties (cognitive) are sources of decreased student performance. Student's achievements can be improved if educating them on how to deal with stressful situations in academic life. If students can cope with their emotional anxiety, this can help achieve better results (Akinsola \& Nwajei, 2013). The results of the study of positron emission tomography (PET) showed that people in extreme situations with emotions of fear, anxiety, and also patients with social anxiety disorders have an increased activity of the tonsils, hippocampus, prefrontal and parietal-temporal areas of the cortex (Furmark et al., 2002; Pavlenko, 2005; Etkin et al., 2005) It should be noted that anxiety performs certain functions: a protective and adaptive function children and adolescents often need this experience. Since it reflects habitual ideas about oneself, habitual self-esteem and emotional well-being (Mohammed, 2016). Most 
often, anxiety is considered as a negative state associated with stressful experiences. The state of anxiety can vary in intensity and change over time as a function of the level of stress that an individual is exposed to, but experiencing anxiety is common to any person in adequate situations (Steinmayr et al., 2016Although anxiety is a common undeniable phenomenon in human beings' life that affect performance and effectiveness in different situations, an average level of anxiety is useful in keeping people hardworking and responsible of what they have to do. It also helps people to have a more sustainable and prosperous life (Kahan, 2008; Donnelly, 2009). The idea of the existence of positive anxiety was developed in the works of Spielberger (2013).

There are two forms of anxiety:

1) Situational anxiety, which is generated by some specific external situation, which objectively causes concern. This condition occurs in any person in anticipation of possible troubles and life complications. This condition is not only completely normal, but also plays a positive role, since it acts as a mobilizing mechanism that allows a person to seriously and responsibly solve the emerging problems. With reduced situational anxiety, a person in the face of serious circumstances demonstrates irresponsible behavior, which most often indicates an infantile life position (Spielberger, 2013; Uvarova \& Kedyarova, 2014).

2) Personal anxiety manifests itself in stable individual differences, in the individual's tendency to experience anxiety in a variety of life situations, including those that are not objectively disposed of to this. The level of personal anxiety is determined based on how often and how intensely an individual has an anxiety state. It is characterized by a state of unaccountable fear, an indefinite sense of threat, and a readiness to perceive any event as unfavorable and dangerous. A person subject to such a state is constantly in a wary and depressed mood, he/she has difficult contacts with the outside world, which he/she perceives as hostile. An inverse relationship is noted of anxiety with such personality traits as social activity, desire for leadership, emotional stability (Zeidner, 2004; Spielberger, 2013; Uvarova \& Kedyarova, 2014).

Anxiety is a signal of danger. It draws attention to possible difficulties, obstacles to achieving the goal, it allows one to mobilize strength and thereby achieve the best result. Therefore, the normal level of anxiety and fear is considered necessary for effective adaptation to reality and is common to all people (Congard et al., 2011). With low motivation, anxiety increases activity and helps to achieve a high result. Anxiety encourages to search and specify the danger. It also encourages active investigation of the situation to identify a threatening factor (Polshkova, 2013). With high motivation, anxiety reduces the level of activity and the desire for high results (Schwarzer, 2013).

Although there are many studies on the relationship between anxiety, motivation, and academic performance, there are still few studies on determining whether there is a positive effect of anxiety on academic performance (Seel, 2012). In accordance with existing problematics, the goal of the study is to determine the effect of anxiety on academic performance. The authors of the current study define positive anxiety as the optimal level of anxiety, which is a necessary condition for the development of 
personality and motivation increase. To achieve the goal of the study, the following objectives are formed:

1. Identifying the relationship between anxiety and performance.

2. Determining the level of motivation depending on the level of trait and state anxiety.

\section{METHOD}

\section{Participants}

658 students of UAE University voluntarily participated in the study: 307 women and 351 men aged 19 to 25 years, average age -22.7 years \pm 1.3 .

\section{Data}

This survey was conducted using an anonymous online survey during the session. The questionnaire indicated age, gender and level of achievement (A, B -high; C, D, E low). The Academic Motivation Scale AMS was used to determine student's motivation (Vallerand et al., 1992), a twenty-eight-item scale. The scales consist of three intrinsicmotivation subscales (12 items):

1. Intrinsic Motivation orientation towards stimulating experiences (IMse);

2. Intrinsic Motivation orientation towards achievement (IMa);

3. Intrinsic Motivation orientation towards knowledge (IMk).

The scales also consist of three extrinsic-motivation subscales (12 items):

1. Extrinsic Motivation identified regulation (EMidr);

2. Extrinsic Motivation introjected regulation (EMintr);

3. Extrinsic Motivation external regulation (EMer).

The scales as well consist of one amotivation subscale (4 items). Evaluation of the AMS showed good internal consistency within the subscales (an average of Cronbach's $\alpha=0.84$ across the seven subscales) (Cronbach, 1951). Other evidence for the construct validity of using AMS for measuring academic motivation is the correlation found in subscale of AMS and related motivational behaviors. Such as a correlation between the amotivation subscale and concentration in class, $\mathrm{r}(218)=-.33, \mathrm{p}<.05$, and correlations ranging between the three intrinsic motivation subscales and positive emotions in class, from $\mathrm{r}(218)=.24$ to $\mathrm{r}(218)=.33, \mathrm{p}<.05$, (Vallerand et al., 1993). Each subscale has four survey items of a 7-point Likert scale. To each item, students rated themselves on a scale of 1 ('Strongly Disagree') to 7 ('Strongly Agree'). A motivation score was calculated for each category (intrinsic, extrinsic, and amotivation) by averaging the score of all items in the subscales within the category. At least $80 \%$ of the items in the category have to be available for a score to be calculated. 
The State-Trait Anxiety Inventory (STAI) was used for determining the level of anxiety (Spielberger et al., 1983). The STAI measures two types of anxiety - state anxiety, or anxiety about an event, and trait anxiety, or anxiety level as a personal characteristic. The STAI is a psychological inventory based on a 4-point Likert scale and consists of 40 questions on a self-report basis. The 4-point scale for State-anxiety is as follows: 1) not at all, 2) somewhat, 3) moderately so, 4) very much so. The 4-point scale for Traitanxiety is as follows: 1) almost never, 2) sometimes, 3) often, 4) almost always. When interpreting indicators, the following indicative estimates of anxiety are used: up to 30 points - low, 31 - 44 points - moderate; 45 and more - high (Spielberger et al., 1983).

In order to trace the relationship between anxiety, motivation and achievement, students were divided into two groups with high and low academic performance.

\section{Statistical Analysis}

Analysis of the data presented in the study was performed in the STATISTICA system. The margin of error is $3.9 \%$, part of the questionnaires was incorrectly completed (for example, some respondents did not answer all the questions in the questionnaire). The data collected were analyzed using Pearson correlation coefficients. The statistical level was determined to be significant if $\mathrm{p}<0.05$

\section{Research Limitations}

The main limitation of the study was a limited sample, since the survey was conducted on the basis of one university. When processing the received data, such details as gender, race, personal source data were not taken into account. Therefore, for a broader study, it will be necessary to take into account not only the age of the students, but also their gender and the initial state of their personality. It is important to note that the results of this study provide only correlation information. The authors could not compare the motivational level of students in the past ant thus could not find out how the motivation of students has changed due to their decisions. A longitudinal study may be able to solve the problem of causality.

\section{FINDINGS AND DISCUSSION}

Indicators of the general level of anxiety, depending on the high and low levels of performance, are shown in Fig. 1. 


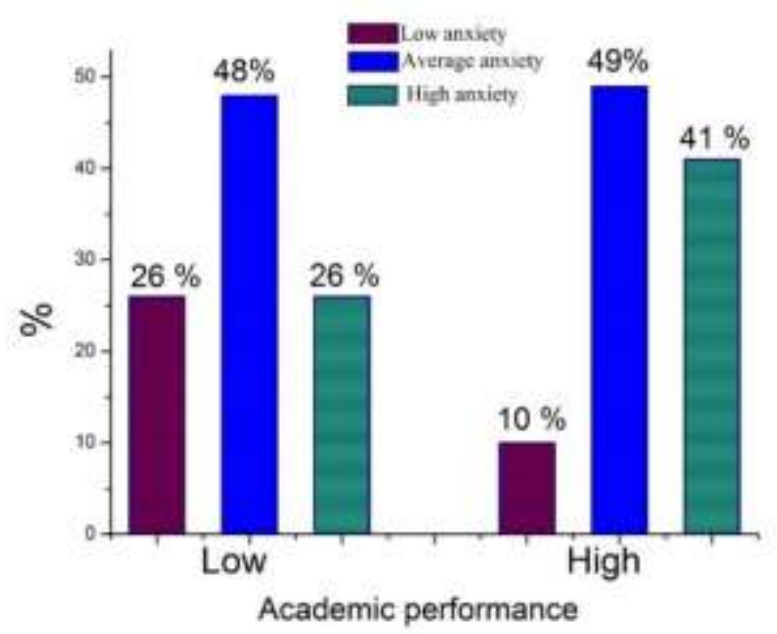

Figure 1

The Level of Anxiety in Students with High and Low Academic Performance (Low $\mathrm{N}=254$; High $\mathrm{N}=404$ )

Fig. 1 indicates that $49 \%$ of high-performing students have moderate anxiety, and $41 \%$ experience high anxiety. High-performing students are $15 \%$ more anxious in comparison to those with low performance. The average level of anxiety in two groups of respondents is almost the same $-48 \%$ and $49 \%$, respectively. This result indicates that education has a high degree of anxiety, which leads to a disorganization of the educational activities of students. The optimal level of anxiety contributes to the successful educational process, based on the activation of attention, thinking, imagination, intellectual abilities of students.

Previous studies have shown that students who have an optimal level of anxiety find the strength and ability to control their emotional state and objectively assess situations (Morosanova, et al., 2020).

The results of the impact of situational anxiety on student motivation are shown in Table 1.

Table 1

Statistics of Measured Variables for State Anxiety

\begin{tabular}{llllllll}
\hline Variables & \multicolumn{3}{l}{ High anxiety } & \multicolumn{3}{l}{ Middle anxiety } & \multicolumn{2}{l}{ Low anxiety } \\
& $\mathrm{N}=108$ & & $\mathrm{~N}=391$ & & $\mathrm{~N}=157$ & \\
\hline Motivation & Mean & $\mathrm{SD}$ & Mean & SD & Mean & SD & $\mathrm{P}$ \\
Intrinsic & 15.34 & 1.56 & 25.77 & 1.05 & 20.11 & 1.76 & 0.04 \\
Extrinsic & 14.21 & 0.98 & 23.26 & 0.87 & 18.95 & 0.87 & 0.03 \\
Amotivation & 9.11 & 1.12 & 8.61 & 0.98 & 7.72 & 1.12 & 0.03 \\
\hline
\end{tabular}


The data in Table 1 indicate that there is statistical significance between the levels of anxiety and the subcategories of motivation $p<0.05$. High rates of internal and external motivation are among respondents with an average value of situational anxiety $(\mathrm{M}=$ 25.77 $\mathrm{SD}=1.05$ and $\mathrm{M}=24.26 \mathrm{SD}=0.87)$. Students with a high level of situational anxiety $(\mathrm{M}=15.34 \mathrm{SD}=1.56)$ have a significantly lower motivation compared to the average $(\mathrm{M}=23.26 \mathrm{SD}=0.87)$ and low $(\mathrm{M}=18.95 \mathrm{SD}=0.87)$ levels. Anxiety scores for the Amotivation category were not significant. These results also indicate that the indicators of Intrinsic motivation $(\mathrm{M}=25.77 \mathrm{SD}=1.05)$ are higher (although slightly) than Extrinsic motivation $(\mathrm{M}=23.26 \mathrm{SD}=0.87)$.

In addition, Intrinsic motivation with an average level of Trait Anxiety $(\mathrm{M}=22.53 \mathrm{SD}=$ $1.00)$ is lower than the State Anxiety $(\mathrm{M}=25.77 \mathrm{SD}=1.05)$, see Table 1 and Table 2.

Table 2

Statistics of Measured Variables for Trait Anxiety

\begin{tabular}{|c|c|c|c|c|c|c|c|}
\hline \multirow{2}{*}{$\begin{array}{l}\text { Variables } \\
\text { Motivation }\end{array}$} & \multicolumn{2}{|c|}{$\begin{array}{l}\text { High anxiety } \\
N=113\end{array}$} & \multicolumn{2}{|c|}{$\begin{array}{l}\text { Middle anxiety } \\
\mathrm{N}=361\end{array}$} & \multicolumn{3}{|c|}{$\begin{array}{l}\text { Low anxiety } \\
\mathrm{N}=184\end{array}$} \\
\hline & Mean & SD & Mean & SD & Mean & SD & $\mathrm{P}$ \\
\hline Intrinsic & 12.27 & 1.34 & 22.53 & 1.08 & 19.61 & 1.54 & 0.03 \\
\hline Extrinsic & 11.23 & 1.33 & 21.26 & 1.17 & 18.57 & 1.67 & 0.03 \\
\hline Amotivation & 9.81 & 1.02 & 7.83 & 0.95 & 7.11 & 1.31 & 0.03 \\
\hline
\end{tabular}

$\mathrm{p}<0.05$

The results of the influence of Trait Anxiety on motivation indicate that the highest rate of Intrinsic motivation (Mean $=22.53 \mathrm{SD}=1.08$ ) is in students with Middle anxiety. Students with a high level of trait anxiety (Mean $=11.23 \mathrm{SD}=1.33$ ) have significantly lower motivation compared to Middle anxiety (Mean $=21.26 \mathrm{SD}=1.17$ ) and Low anxiety $($ Mean $=16.57 \mathrm{SD}=1.67)$. For students with Low trait anxiety $($ Mean $=21.26$ $\mathrm{SD}=1.17)$ and Middle anxiety $($ Mean $=18.57 \mathrm{SD}=1.67)$, the difference in indicators is insignificant.

Most cross-sectional studies have shown a negative correlation between test anxiety and performance (e.g. Cassady \& Johnson, 2002; Nicholson, 2009). However, little is known about factors that can mitigate the impact of test anxiety on academic performance (Barrows et al., 2013). In the literature, it is widely believed that test anxiety is associated with poor academic performance. Scientists have found an inverse relationship between test anxiety and academic effectiveness (Chapell et al., 2005; Yakub et al., 2011).

In this study, the authors determined the relationship between anxiety and academic performance. Students with high and medium levels of anxiety have high results in academic performance. Effective learning and harmonious life require a certain useful level of anxiety. Therefore, according to the study results, students mostly have the internal motives associated with an interest in learning activities, a sense of obtaining competence. At the same time, external motives (study as a duty) and external coercion from parents and teachers play a lesser role for students. Analyzing the level of anxiety, it was revealed that students with an average level of situational anxiety have the highest rates of motivation. Situational anxiety is characterized by stress, anxiety. Such 
conditions arise as an emotional reaction to a stressful situation, which contributes to the need to find solutions and motivates to perform certain actions. Motivation and anxiety as personal dispositions are closely interconnected. The level of situational and personal anxiety depends on a particular motivational tendency ( $\mathrm{Su}, 2017)$. The normal level of anxiety positively affects students' motivation and achievement. However, some scientists have established negative correlation $(0.17$ for $\rho<0.04)$ between a high level of situational anxiety and a low level of educational motivation. That is, the higher the level of situational anxiety, the lower the level of educational motivation (Arkaeva, 2015). Those students with high level of anxiety and low level of motivation tend to perform poorly (not using their capabilities) - even when they have high level of skills and abilities (Raccanello et al., 2019). Researchers point to the obvious relationship between anxiety and the effectiveness of schooling. Psychologists note that training is often accompanied by increased anxiety in children (Putwain et al., 2019). However, anxiety can act as an activator of the learning process, making it successful and effective because it mobilizes the attention, memory, intellectual abilities of the child, and as a negative factor preventing children from realizing their learning activities (Harley et al., 2019).

In the case of high and moderate anxiety, conscious self-regulation is also important, which can become a personal resource that helps to ensure the reliability of actions in stressful conditions, as shown by the results of the study (Morosanova et al., 2019). Pupils with a high level of positive (optimal) anxiety, demonstrate obedience, performability, focus on the exact completion of tasks and perfectionism. The desire to do the job as best as possible leads to inefficiency of activity at the expense of constant re-checking, fixation on random trifles, etc. The latter contribute to distraction from the basic meaning of the task being performed, additional waste of time and effort and an increase in anxiety level.

\section{CONCLUSIONS}

Based on the results of the study, it can be concluded that students with high and medium levels of anxiety have high results in academic performance, and students with low academic performance have a low level of anxiety respectively. High rates of internal and external motivation are among respondents with an average value of situational and personal anxiety. Low motivation indicators are observed among students with high situational and personal anxiety. These results indicate that the student's average level of anxiety positively affects both academic performance and motivation. A high level of anxiety contributes to a high level of academic achievement, but at the same time reduces the motivation for learning. A low level of anxiety leads to a decrease in academic performance, but the level of motivation is quite high. It is also worth noting that the level of anxiety does not affect the students' self-motivation. These studies can be useful in organizing the educational process at the university, and when working with anxious students. 


\section{REFERENCES}

Akinsola, E. F., \& Nwajei, A. D. (2013). Test anxiety, depression and academic performance: assessment and management using relaxation and cognitive restructuring techniques. Psychology, 4, 18-24.

Arkaeva, M. Yu. (2015). Studying the impact of situational anxiety on the educational motivation of elementary school students. Concept, 18, 51-55.

Barrows J., Dunn S., \& Lloyd C. A. (2013). Anxiety, self-efficacy, and college exam grade. Universal Journal of Education Research, 1, 204-208.

Cassady, J. C., \& Johnson, R. E. (2002). Cognitive test anxiety and academic performance. Contemp. Educ. Psychol., 27, 270-295.

Chapell, M. S., Blanding, Z. B., Silverstein, M. E., Takahashi, M., Newman, B., Gubi, A., \& McCann, N. (2005). Test anxiety and academic performance in undergraduate and graduate students. Journal of educational Psychology, 97(2), 268.

Congard, A., Dauvier, B., Antoine, P., \& Gilles, P. Y. (2011). Integrating personality, daily life events and emotion: Role of anxiety and positive affect in emotion regulation dynamics. Journal of Research in Personality, 45(4), 372-384.

Cronbach, L. (1951). Coefficient alpha and the internal structure of tests. Psychometrika, 16, 297-334.

Donnelly, R. (2009). Embedding interaction within a blend of learner centric pedagogy and technology. World Journal on Educational Technology, 1(1), 6-29.

Dweck, C. S., \& Wortman, C. B. (1982). Learned helplessness, anxiety, and achievement motivation: Neglected parallels in cognitive, affective, and coping responses. Series in Clinical \& Community Psychology: Achievement, Stress, \& Anxiety, 93-125.

Eccles, J. S., \& Wigfield, A. (2002). Motivational beliefs, values, and goals. Annu. Rev. Psychol., 53, 109-132.

Erzen, E. (2017). The effect of anxiety on student achievement. In E. Karadağ (Ed.), The factors effecting student achievement (pp.75-94). Springer, Cham.

Etkin, A., Pittenger, C., Polan, H. J., \& Kandel, E. R. (2005). Toward a neurobiology of psychotherapy: basic science and clinical applications. The Journal of Neuropsychiatry and Clinical Neurosciences, 17(2), 145-158.

Eysenck, M. W., Derakshan, N., Santos, R., \& Calvo, M. G. (2007). Anxiety and cognitive performance: Attentional control theory. Emotion, 7, 336-353.

Furmark, T., Tillfors, M., Marteinsdottir, I., Fischer, H., Pissiota, A., Långström, B., \& Fredrikson, M. (2002). Common changes in cerebral blood flow in patients with social phobia treated with citalopram or cognitive-behavioral therapy. Archives of General Psychiatry, 59(5), 425-433. 
Guo, J., Parker, P. D., Marsh, H. W., \& Morin, A. J. (2015). Achievement, motivation, and educational choices: A longitudinal study of expectancy and value using a multiplicative perspective. Developmental Psychology, 51(8), 1163.

Hailikari, T., Tuononen, T., \& Parpala, A. (2018). Students' experiences of the factors affecting their study progress: Differences in study profiles. Journal of Further and higher Education, 42(1), 1-12.

Hancock, D. R. (2001). Effects of test anxiety and evaluative threat on students' achievement and motivation. The Journal of Educational Research, 94(5), 284-290.

Harley, J. M., Jarrell, A., \& Lajoie, S. P. (2019). Emotion regulation tendencies, achievement emotions, and physiological arousal in a medical diagnostic reasoning simulation. Instructional Science, 47(2), 151-180.

Hol, D., \& Yavuz, A. (2017). The role of socio economic status on the EFL learners' attributions on success and failure. International Journal of Liberal Arts and Social Science, 5(9), 29-38.

Jing, H. (2007). Analysis on the relationship among test anxiety, self-concept and academic competency. US-China Foreign Language, 5(1), 48-51.

Kahan, L. M. (2008). The correlation of test anxiety and academic performance of community college students (Unpublished doctoral dissertation). Capella University.

Kenny, M. E., Walsh-Blair, L. Y., Blustein, D. L., Bempechat, J., \& Seltzer, J. (2010). Achievement motivation among urban adolescents: Work hope, autonomy support, and achievement-related beliefs. Journal of Vocational Behavior, 77(2), 205-212.

Khalaila, R. (2015). The relationship between academic self-concept, intrinsic motivation, test anxiety, and academic achievement among nursing students: Mediating and moderating effects. Nurse Education Today, 35(3), 432-438.

Mohammed, A. (2016). EFL effective factors: anxiety and motivation and their effect on Saudi college student's achievement. Arab World English Journal (AWEJ), 6(2), 201218.

Mondal P., Ghosh A., \& Das S. S. (2013). Relationship between anxiety and achievement motivation of chess players. Physical Education, 3, 443-444.

Morosanova, V. I., \& Filippova, E. V. (2019). What ensures reliability of a student's actions in an examination. Vopr. Psikhol., 1, 65-78.

Morosanova, V., Fomina, T., \& Filippova, E. (2020). The relationship between the conscious self-regulation of schoolchildren's learning activity, their test anxiety level, and the final exam result in mathematics. Behavioral Sciences, 10(1), 16.

Muro, A., Soler, J., Cebolla, À., \& Cladellas, R. (2018). A positive psychological intervention for failing students: Does it improve academic achievement and motivation? A pilot study. Learning and Motivation, 63, 126-132. 
Nicholson, A. M. (2009). Effects of test anxiety on student achievement (ACT) for college bound students. Diss. Abstr. Int., 70, 2400.

Pavlenko, O. M. (2005). Neurobiological approach to the study of the effects of psychotherapy. Scientific notes of V.I. Vernadsky Taurida National University. Series "Biology, Chemistry", 18 (57) (3), 107-114

Polshkova T. A. (2013). The problem of situational anxiety in psychological and pedagogical research. Current problems of modern psychology: Materials of the II Intern. scientific conf. Chelyabinsk: Dva Komsomoltsa.

Putwain, D. W., Loderer, K., Gallard, D., \& Beaumont, J. (2019). School-related subjective well-being promotes subsequent adaptability, achievement, and positive behavioural conduct. British Journal of Educational Psychology, 90(1), 92-108.

Raccanello, D., Brondino, M., Moè, A., Stupnisky, R., \& Lichtenfeld, S. (2019). Enjoyment, boredom, anxiety in elementary schools in two domains: Relations with achievement. The Journal of Experimental Education, 87(3), 449-469.

Rana, R., \& Mahmood, N. (2010). The relationship between test anxiety and academic achievement. Bulletin of Education and Research, 32(2), 63-74.

Schwarzer, R. (2013). Self-related cognitions in anxiety and motivation: An introduction. In R. Schwarzer (Ed.), Self-related cognitions in anxiety and motivation (pp.1-18). Psychology Press.

Spielberger, C. D. (2013). Anxiety: Current trends in theory and research. Elsevier.

Spielberger, C. D., Gorssuch, R. L., Lushene, P. R., Vagg, P.R., \& Jacobs, G. A. (1983). Manual for the state-trait anxiety inventory. Consulting Psychologists Press.

Steinmayr, R., Crede, J., McElvany, N., \& Wirthwein, L. (2016). Subjective well-being, test anxiety, academic achievement: Testing for reciprocal effects. Frontiers in Psychology, 6, 1994.

Steinmayr, R., Wirthwein, L., \& Schöne, C. (2014). Gender and numerical intelligence: does motivation matter? Learn. Individ. Diff., 32, 140-147.

Su, C. H. (2016). The effects of students' motivation, cognitive load and learning anxiety in gamification software engineering education: a structural equation modeling study. Multimedia Tools and Applications, 75(16), 10013-10036.

$\mathrm{Su}, \mathrm{C} . \mathrm{H}$. (2017). The effects of students' learning anxiety and motivation on the learning achievement in the activity theory based gamified learning environment. EURASIA Journal of Mathematics, Science and Technology Education, 13(5), 12291258.

Toraman, Ç., Özdemir, H. F., Koşan, A. M. A., \& Orakc1, Ş. (2020). Relationships between cognitive flexibility, perceived quality of faculty life, learning approaches, and academic achievement. International Journal of Instruction, 13(1), 85-100. 
Uvarova, M. Yu., \& Kedyarova, E. A. (2014). Study of personal anxiety and achievement motivation among first-year students. News of Irkutsk State University. Series: Psychology, 8, 74-86.

Vallerand, R. J., Pelletier, L. G., Blais, M. R., \& Brière, N. M. (1992). The academic motivation scale: A measure of intrinsic, extrinsic, and amotivation in education. Educational and Psychological Measurement, 52(4), 1003-1017.

Vallerand, R. J., Pelletier, L. G., Blais, M. R., Briere, N. M., Senecal, C., \& Vallieres, E. F., (1993). On the assessment of intrinsic, extrinsic, and amotivation in education: Evidence on the concurrent and construct validity of the academic motivation scale. Educational and Psychological Measurement, 53(1), 159-172.

Wigfield, A., Eccles, J. S., Schiefele, U., Roeser, R. W., \& Davis-Kean, P. (2006). Development of achievement motivation. In N. Eisenberg, W. Damon, \& R. M. Lerner (Eds.), Handbook of child psychology: Social, emotional, and personality development (pp.933-1002). Hoboken, NJ: John Wiley \& Sons

Yakub, A. S., Abelite, L. L., \& Shiryaev, D. A. (2011). Relation of anxiety with motivation to achieve success and avoid failure (female aspect of the problem). Young Scientist, 9, 174-180.

Zeidner, M. (2004). Test anxiety. In C. D. Spielberger (Ed.), Encyclopedia of applied psychology (pp.545-556). Academic Press. 